\title{
Psychosocial problems and development of psychopathology among Ugandan university students
}

\author{
Nsereko, Norman David $₫$ \\ Nkumba University, Uganda (nserekon@gmail.com) \\ Musisi, Seggane \\ Makerere University, Uganda (segganemusisi@yahoo.ca) \\ Nakigudde, Janet \\ Makerere University, Uganda (jnakigudde@chs.mak.ac.ug) \\ Ssekiwu, Denis \\ Muteesa 1 Royal University, Uganda (Dsekiwu1@yahoo.co.uk)
}

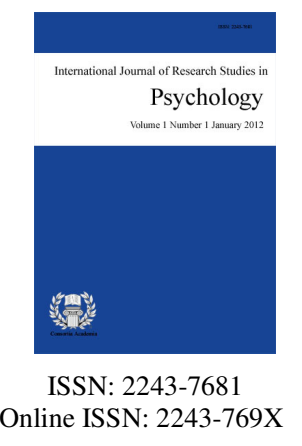

OPEN ACCESS

\section{Abstract}

The impact of psychosocial problems on the development of psychopathology (depression/anxiety) among university students is an area that greatly remains unexplored leading to insufficient assessment of the mental health status of the students. Consequently, students' psychosocial problems and psychopathology if left untreated and unchecked, they may severely interfere in their everyday functioning and manifest compromised social cohesion, mental health and wellbeing, with the increased likelihood of future instability and conflict. The aim of the study was to address a broader understanding of a multidimensional aspect of psychosocial problems to the development of psychopathology (anxiety, depression) for university students in Uganda. It was hypothesized that there is no relationship between exposure to psychosocial problems and the development of psychopathology. This cross-sectional study was a secondary analysis of data from the $\mathrm{PhD}$ study on development and validation of an instrument to measure psychosocial problems of university students. The University Students Evaluation of Psychosocial Problems (USEPP) instrument was used to evaluate psychosocial problems. The two symptoms of psychopathology denoting common mental disorders were measured using the Hopkins Symptom Checklist 10 (HSCL-10). Regression analysis was performed to establish the relationship between psychosocial problems and psychopathology. The findings of this study revealed that students having psychosocial problems were significantly related to the development of psychopathology. The findings highlight to the need to put intervention measures to address the students' psychosocial problems and mental health disorders by putting counselling infrastructure in institutions of learning to address the mental health needs of the students.

Keywords: mental health; university students; counselling services 


\section{Psychosocial problems and development of psychopathology among Ugandan university students}

\section{Introduction}

The mental health of the university-age population has received heightened attention (Hunt \& Eisenberg, 2010; Gallagher, Zhang, \& Taylor, 2004) with increased perception that the number of students with severe psychological problems has gone up in recent years (Kitzrow, 2003; Gallagher, 2006; Blanco, Okuda, Wright, Hasin, \& Grant et al., 2008).

The students face multiple protective and risk factors to developing psychopathology like, many students lead "hyper-enriched lives", with their cell phones, computers, classes, jobs, sports, travel, volunteer work, and more (Kneser, 2004); being young adults, and in some parts of the world have serious financial problems, development of personal relationships, and for some, parenthood, pursuit of greater educational opportunities and employment prospects (Mikolajczyk, Brzoska, Maier, Ottova, Meier et al., 2008); Blanco et al., 2008); academic unreadiness, inadequate study habits (Harper \& Peterson, 2005); cross-cultural issues, family dysfunction, poor frustration tolerance, experimentation with drugs and alcohol, and weak interpersonal attachments (Kitzrow, 2003); academic overload, constant pressure to succeed, competition with peers and concerns about the future (Tosevski, Milovancevic, \& Gajic, 2010).

These psychosocial experiences directly impact on students' ability to function effectively in classrooms, family settings, and social activities. Often they result in unprecedented study burn out among students with consequent various forms of psychopathology among this population than in other populations which may persist later in life (Kitzrow, 2003; Harper \& Peterson, 2005).

The students enrolled at the universities in Uganda like their counterparts in western universities can face numerous stressors that have been known to contribute to their development or exacerbation of mental health problems. Despite these happenings, university infrastructure growth in Uganda has been slow in matching the increasing enrolments (UNCST, 2011) and in particular the aspect of mental health on Uganda university campuses has not been given the attention it deserves (Ovuga, Boardman, \& Wasserman, 2006).

Much less is known about the risk factors to psychopathology among university students or the relationship between psychosocial problems and psychopathology or the impact on academic performance. A paucity of available studies on Uganda university students' mental health has concentrated on the prevalence of the different symptoms of psychopathology among the students (Ovuga et al., 2006). Of much concern in this study is the aspect of a multidimensional framework of psychosocial problems which combines both the internalizing and externalizing aspects namely emotional, academic, antisocial behavior problems and traumatic experiences captured on a single scale (The University Students Evaluation of Psychosocial Problems: USEPP) to predict the development of psychopathology among university students. This aspect has not been established nor systematically investigated in Uganda and elsewhere. Understanding the relationship between a multidimensional aspect of psychosocial problems and psychopathology is not only of theoretical importance but may also have implications for devising counselling interventions directed at the negative effects of psychosocial problems and psychopathology on the students' general functioning.

\section{Literature Review}

\subsection{Psychosocial problems among students}

Psychosocial problems have been described as the maladaptive, negative or unhealthy intrapersonal 
emotional and behavioral states, and they often lead to maladaptive, negative and unhealthy interpersonal networks, human relationships, social connections and social malfunctioning (Laelia, Apicella, Brakarsh, Dube, Jemison et al., 2006). Researchers on the psychosocial problems that people in general encounter have concluded that the topic needs more attention because of their impact on mental health (Ellison, 2004; Ontari \& Angolla, 2008). Significant psychosocial problems once they remain for a sustained period of time and/or if social supports are unavailable they negatively impact on mental health often leading to development of significant psychopathology (Ellison, 2004; Ontari \& Angolla, 2008; Holmes, Silvestri, \& Kostakos, 2011; Williams \& Galliher, 2006). For instance psychosocial problems among adolescents living in Internally Displaced Persons Camps in northern Uganda were found to be associated with development of mental health disorders especially depression, anxiety, substance abuse even psychosis (Betancourt, Speelman, Onyango, \& Bolton, 2009).

Psychosocial problems other than psychiatric illness have been shown to occur among university students at study time or examination times and in relation to entering university and in relation to important events in the student's personal and family life (Lucas, 1976). Ahmad, Khalique, Khan, and Amir (2007) noted that psychosocial problems are often widely ignored for intervention and that where there was lack of mental health services, academic underachievement and antisocial behaviuor were notably increased among the students.

Students' psychosocial problems constitute a topic of rising interest around the world and in a wide variety of settings especially in the students' educational career as they impact the students' mental health and academic performance (Omokhodion \& Gureje, 2003; Lucas, 1976).

Buckley (2009) found that $1 / 3$ of students failed to learn because of psychosocial problems as these impaired student's ability to attend to and engage fully in instructional activities. In the US, student psychosocial problems were reported to be increasing among students in institutions of higher learning and often resulting in serious mental illness (ACHA, 2006). In that report 10\% college students with psychosocial problems reported attempting suicide.

Reijneveld, Vogels, Brugman, Van Ede, Verhulst et al. (2003) observed that early identification and treatment of students' psychosocial problems reduced the development or severity of psychopathology. However little is known about potential risk factors for psychosocial problems within young adults including university students in particular. Instead much literature has focused on manifest pathological syndromes such as depression or anxiety (Eisenberg, Gollust, Golberstein, \& Hefner, 2007).

\subsection{Psychopathology among students}

A growing body of research suggested that psychological distress conditions were numerous and increasing among students in institutions of higher education. For instance research in the UK indicated that mental health illness or psychological problems within student populations were as high as $40 \%$, with most students suffering from depression or anxiety, or both (Sherina, Med, Rampal, \& Kaneson, 2004). Gallagher (2005) cited out that $86 \%$ of university students reported severe psychological problems including depression, anxiety and serious substance abuse at counselling centers. Further still, recent systematic reviews of universities worldwide concur with earlier findings which indicated an apparent trend of worsening mental health in recent years among the university population with significant numbers of students with serious mental illness rising up (Hunt \& Eisenberg, 2010; Storrie, Ahern, \& Tuckett, 2010). In a maiden study about experiences of depressed mood among students at a South African university, students were found to have higher rates of depression and suicidal ideation than the general population. Over $14.9 \%$ of the students were diagnosed with a major depressive disorder which is significant considering the lifetime prevalence of major depressive disorder being between $5 \%$ and 25\% (Van Niekerk, Viljoen, Rischbleter, \& Scribante, 2008).

The associated psychopathology often manifested as depression and anxiety which was often referred to as "stress" by the university students was singled out to lead to difficulties in concentration, lack of motivation and interest, poor attendance, and somatic physical complaints such as headaches, poor sleep and fatigability 
Nsereko, N. D., Musisi, S., Nakigudde, J., \& Ssekiwu, D.

(Dusselier, Dunn, Wang, Shelly, \& Whalen, 2005). Salzer (2012) reported that college students with emotional distress reported less engagement on campus activities and exhibited poorer relationships, which factors were associated with lower graduation rates. In another study, Pledge, Lapan, Heppner, and Roehlke (1998) observed that in addition to adjustment and individuation challenges, university students reported severe psychopathology that included suicidality, substance abuse, history of psychiatric treatment or hospitalization, depression and anxiety.

Long term follow up studies have shown that students' psychosocial problems and psychopathology if left unchecked, may severely interfere students' future everyday functioning and manifest as compromised social cohesion, poor mental health and compromised wellbeing, with the increased likelihood of future instability and conflict (Blignault, Bunde-Birouste, Ritchie, Silove, \& Zwi, 2009).

\subsection{Missing gaps in understanding the development of students' psychopathology}

A critical review of current literature and research reveals a number of gaps in understanding university students' mental health and the risk factors to the development of psychopathology. University student's mental health problems are constructed within increasingly narrow theoretical, clinical and research frameworks. These emphasize a medical and pathology based construction of student's behavior, rather than one that takes into account the meaning of student's psychosocial contextual variables (Mowbray \& Holter, 2002; Engel, 1977; Ovuga et al., 2006).

A report by Hunt and Eisenberg (2010) that reviewed the research literature on college student mental health, revealed that the most researched conceptual framework on psychopathology among university students was on prevalence. Another equally researched area was the influence of psychopathology on students' academics (Kendall \& Dobson, 1993; Bodas, 2003; Brackney \& Karabenick, 1995; Svanum \& Zody, 2001; Md Yasin \& Dzulkifli, 2009) and yet those that have studied the risk factors among college students to the development of psychopathology have concentrated on demographics e.g. race (Hasin, Stinson, \& Grant, 2007); sex (Silverman, Meyer, Sloane, Raffel, \& Pratt,1997); socioeconomic backgrounds (Eisenberg et al., 2007; Weitzman, 2004); while others who have studied psychosocial issues as risk factors to psychopathology have concentrated on individual factors e.g. relationship stressors (Kisch, Leino, \& Silverman, 2000); low social support (Blanco, et al., 2008)., or victimization by sexual violence (Stepakoff, 1998); and personality traits (Tosevski et al., 2010; Miller, Schmidt, \& Vaillancourt, 2008). These studies have considered a unidimensional approach to establish the factors leading to the development of psychopathology. Others factors to the development of psychopathology have been based on counseling center staff perceptions (Pledge et al., 1998; Gallagher et al., 2004; Stone \& Archer, 1990; Kitzrow, 2003) which are compounded by several key methodological issues (Kettmann, Schoen, Moel, Cochran, Greenberg et al., 2007).

Therefore this study tries to address a broader understanding of a multidimensional aspect of psychosocial problems to the development of psychopathology (anxiety, depression) for university students in Uganda.

\subsection{Hypothesis}

There is no relationship between exposure to psychosocial problems as measured by USEPP and development of psychopathology among university students.

\section{Methodology}

\subsection{Study Design}

This study was part of a longer $\mathrm{PhD}$ study that validated an instrument for assessing university students' psychosocial problems (The University Students Evaluation of Psychosocial Problems: USEPP). The study 
Psychosocial problems and development of psychopathology among Ugandan university students

employed a cross-sectional descriptive study design using a quantitative approach because all variables in this research were measured instead of being manipulated. The study was approved by the Nkumba University Internal Review Board and Uganda National Council of Science and Technology for IRB clearance.

\subsection{Participants and Recruitment}

The sample size was 1500 randomly selected from undergraduate university students in three purposively chosen universities in Uganda: one public and two private. The actual number recruited per university was chosen for proportionate representation of the student body of that university. Out of 1500 students who agreed to participate, 1427 respondents $(95 \%)$ had correctly completed the questionnaires. Seventy three respondents (5\%) either did not have completed questionnaires or some did not voluntarily hand in the questionnaires indicating that they withdrew from the exercise. Hence, only 1427 students were included in the study for analysis. The majority of the students were female $55.6 \%$. The biggest group of the participants were aged $\leq 24$ years $(72.5 \%)$, Ugandan (93.6\%), single (88.8\%) and of Christian religious background (79.4\%) with Moslems being $19.1 \%$ and others $1.5 \%$. Most students lived in student accommodation (88\%) either in off campus hostels $(50 \%)$ or on campus hostels $(38 \%)$. In holidays most, $67.2 \%$, lived with their parents, $8.7 \%$ living as married and the rest $(24.1 \%)$ with relatives or alone. The majority of the participants $(96.1 \%)$ were in day study program with only $(3.9 \%)$ in weekend program and they were supported by their parents $(63.8 \%)$ or relatives $(17.6 \%)$ who also paid for their education with only $7.2 \%$ being on government or other (11.4\%) sponsorship. Our participants were mostly in their 3rd $(45.1 \%)$ or 2 rd $(37.4 \%)$ year of study. The three most attended courses were Public Administration (19.6\%), Business Administration (17.7\%) and Guidance/Counselling (10.4\%).

Inclusion criteria - Only undergraduate students from the Arts (Humanities) and Business Studies faculties were recruited.

Exclusion criteria - Postgraduate students, Long Distance Program students, and the science and professional students.

\subsection{Measures}

Demographic information collected included gender, age, religion, nationality, marital status, residence location, living arrangements (with parents or not), program of study, year in university and course of study.

The University Students Evaluation of Psychosocial Problems Scale (USEPP) - The university students' psychosocial problems were measured using a previously developed tool, The University Students Evaluation of Psychosocial Problems Scale (USEPP). The USEPP is a 17 item instrument designed to screen university students in Uganda for psychosocial problems. It was validated against HSCL-10 in non-clinical settings. The 17-item USEPP has four subscales measuring psychosocial problems: (i) Emotional Problems (5 items); (ii) Traumatic Experiences (4 items); (iii) Antisocial Behavior (5 items) and (iv) Academic Problems (3 items). It has a cut off score of 18 to indicate compromised psychosocial function. Each subscale item is rated on a scale as 0 (not at all); 1(somewhat agree); 2 (agree) to 3 (strongly agree). An individual is asked to indicate his/her level of agreement with the items that are current concerns to him/her (Nsereko, Musisi, \& Holtzman, in press). In this study the scale demonstrated internal consistency of 0.81 as measured by Cronbach's alpha.

The Hopkins Symptoms Checklist-10 (HSCL-10) - Psychopathology was defined as having symptoms of depression and or anxiety as measured by the Hopkins Symptoms Checklist-10 (HSCL-10). The HSCL-10 is a widely used psychological distress screening instrument in epidemiological studies and has been validated in Ugandan settings (Nsereko et al, in Press). The HSCL- 10 has a 10- item checklist tapping both anxiety and depression with 4-items indicating anxiety and 6-items indicating depression. Each item is rated on a scale from 1 (not at all) to 4 (extremely). Participants were asked to respond to the items according to their experience during the previous week. In this study the internal consistency as measured by Cronbach's alpha was 0.70. 


\subsection{Procedure}

An invitation was sent out to all students to participate in the study using announcements by lecturers in their respective universities. The purpose of the study, ethical issues and informed consent procedures were explained to the students. The students who gave written consent to the study were served self-administered questionnaires to answer. Additionally, it was indicated that there would be referral information specific at each institution as well as access to counselors for all participants who should be found to be significantly distressed. The instruments were distributed in the months of February to April 2012 to the university student respondents during the course of their lectures. The lecturers and the principal researcher collected the completed questionnaires after the exercise. Each student was requested to complete the questionnaires individually and in privacy without consultation to colleagues or lecturers.

\subsection{Analysis}

The SPSS version 18 for windows was used to analyze data. Descriptive statistics were calculated for descriptive data. Multiple regressions were performed to establish the relationship between psychosocial problems as measured by USEPP and psychopathology as measured by HSCL-10. To test the null hypothesis that there was no relationship between exposure to psychosocial problems and development of psychotherapy, the problematic scores of USEPP were correlated with HSCL-10 problematic scores.

\section{Results}

\subsection{Caseness of psychopathology and Psychosocial problems}

The students who scored $\geq 18$ on the USEPP Scale indicating psychosocial problems were 528 (37\%, $\mathrm{M}=24.3, \mathrm{SD}=6.02$ ). This was an equivalent finding when using the HSCL-10 Scale for comparison where the numbers indicating psychological distress (psychopathology) was 496 (34.8\%, M=25.4, SD=3.25). The most frequent psychosocial problems as shown on the USEPP subscales were traumatic experiences $(47.7 \%, \mathrm{M}=7.11$, $\mathrm{SD}=1.9)$ followed by emotional problems (38.1\%, $\mathrm{M}=9.37, \mathrm{SD}=2.17)$ and academic problems $(32.8 \%, \mathrm{M}=5.49$, $\mathrm{SD}=1.49)$. The least frequent problems were antisocial behavior (18.4\%, $\mathrm{M}=7.95, \mathrm{SD}=2.65)$. Some students had a combination of problems on the subscales.

\subsection{Association of psychosocial problems to psychopathology}

The association of psychosocial problems to development of psychopathology was assessed by logistic regression analysis. The psycho-social problems were predictors and the dependent (outcome) variable was psychopathology (depression and anxiety scores on the HSCL-10). The results indicated a significant relationship between the problematic scores on the USEPP and the psychopathology scores on the HSCL-10 $\left(\mathrm{R}=0.27, p<.01 ; \mathrm{R}^{2}=0.071, p<.01 ; \mathrm{F}=14.74, p<.01\right)$. The null hypotheses were rejected. This meant that having psychosocial problems as indicated on the USEPP (scores $\geq 18$ ) was significantly associated $(p=0.01)$ with development of symptoms of psychopathology (depression and anxiety) as indicated on the HSCL-10 (scores $\geq$ 22).

A follow up multiple regression was done with the 4 subscales of psychosocial problems on the university students (USEPP scores) as predictors and the total psychopathology scores of HSCL-10 as the dependent variable. This regression analysis is shown below on table 1 . The results indicated that only one subscale namely, Antisocial behavior $(\mathrm{r}=-.26 ; p<.05)$ predicted psychopathology. This meant that students who had antisocial behavior were more likely to show psychopathology as depression and or anxiety. There was no significant relationship between the remaining three predicting subscales: Emotions Problems ( $\mathrm{r}-.008 ; p=.913$ ); Traumatic Experiences ( $\mathrm{r}=-.082 ; p=.220)$ and Academic Problems ( $\mathrm{r}=-.081 ; p=.294)$. This finding has treatment (counselling) implications. 
Psychosocial problems and development of psychopathology among Ugandan university students

Table 1

Regression statistics of predictors of psychopathology

\begin{tabular}{lccccc}
\hline \multicolumn{1}{c}{ Predictor } & $\begin{array}{c}\text { Unstandardized } \\
\text { coefficients }(B)\end{array}$ & SE & Beta & $t$ & p-level \\
\hline Psychosocial Problems & -.100 & .026 & -.267 & -3.840 & $0.01^{* *}$ \\
Antisocial Problems & -.194 & .079 & -.260 & -2.471 & $0.05^{*}$ \\
Emotional Problems & -.011 & .098 & -.008 & -1.090 & 0.913 \\
Traumatic Experiences & -.131 & .107 & -.082 & -1.230 & 0.220 \\
Academic Problems & -.158 & .150 & -.081 & -1.053 & 0.294 \\
\hline Note. $* \mathrm{p}<0.05, * * \mathrm{p}<0.01$ & & & & &
\end{tabular}

\section{Discussion}

The main objective of the study was to determine whether students who were exposed to psychosocial problems as shown on the USEPP would also develop the symptoms of psychopathology as shown on the HSCL-10. Results indicated that out of 1427 university student respondents, 528 (37\%) were screened positive for psychosocial problems corresponding to $34.8 \%$ screened positive for psychopathology (depression and anxiety). In regard to specific problems, $47.7 \%$ had experienced traumatic experiences, $38.1 \%$ exhibited emotional problems, $32.8 \%$ had academic difficulties and $18.4 \%$ had antisocial behavior. The findings meant that students who were exposed to psychosocial problems also developed psychopathology manifesting as depression and anxiety.

These findings are consistent with previous studies of risk factors associated with psychopathology among university students which have shown that university students who were exposed to significant stressors developed depression and anxiety (Omokhodion \& Gureje, 2003; Kadison, \& DiGeronimo, 2004; Eisenberg et al., 2007; Salzer, 2012). Significantly also, this study indicated that a combination of several risk factors to develop psychopathology among university students included emotional problems, traumatic experiences, academic problems and antisocial behavior in comparison to what other studies have indicated (Eisenberg et al., 2007; Sherina et al., 2004). These findings could be an argument for universities like Stallman (2008), Stone and Archer (1990) have suggested to co-locate specialist mental health services within a university setting that can promote a team approach to mental health care, with GPs, psychiatrists, clinical psychologists, social workers, student academic advisers, substance use specialists and counselling psychologists working together to increase the availability of care to students in need.

Given the fact that the majority of the students belonged to any particular religious affiliation, faith based services to students should be an integral part of university team to address the students' psychosocial problems. Anecdotal, quantitative and qualitative evidence across a range of disciplines including psychology, psychiatry, theology, nursing and gerontology, acknowledge that spirituality serves as part of an integrative approach to understanding mental health and wellbeing and that it makes a positive contribution to mental health (Cornah, 2012; Renu \& Manju, 2013). Mental health professionals through public-private partnerships may assist clergy in identifying problems and making appropriate referrals (Pickard \& Tang, 2009).

When the individual factors were regressed against the dependent variable of psychopathology only one factor, the antisocial behavior was significant. This indicated that students having antisocial behaviour were more likely to develop psychopathology manifesting as depression and or anxiety on the HSCL-10. This finding concurs with findings from other studies on the impact of antisocial behaviour on an individual. Suffering from antisocial behavior has been found to generate repeated multiple problem behaviours such as conduct problems, truancy and substance use, mental health difficulties, authority conflict problems, aggression etc. (Smart, Vassallo, Sanson, \& Dussuyer, 2004; Loeber \& Farrington, 1998). Other studies have indicated that engagement in antisocial behaviour may be symptomatic of psychiatric illness (Waddell, Lipman, \& Offord, 1999; Robins \& Price, 1991).

Society does not accommodate antisocial behavior leading to a heavy social sanctioning and a burden to 
Nsereko, N. D., Musisi, S., Nakigudde, J., \& Ssekiwu, D.

those engaged in such behavior (Offord \& Bennet, 1994). University students who are involved in antisocial behaviour whether identified or not may thus be experiencing feelings of isolation and dejection from society thus compounding their psychopathology of depression and anxiety.

A possibly surprising result in this study was that the students with psychosocial problems (USEPP scores $\geq 18$ ) on emotion, traumatic and academic subscales were not significantly associated with symptoms of psychopathology. It would seem that such problems though common did not translate in psychopathological states. Emotional, traumatic and academic problems are individualistic and thus ego-syntonic. However antisocial behavior problems involve others, impinge on relationships and are judged/censored by the society (Smart et al., 2004). Thus shame is more likely to generate psychopathology than guilt from self-censorship. This may explain why antisocial behavior problems which involve unacceptable interaction with others mostly likely caused the psychopathology of depression and anxiety. However, this conclusion may need further research for complete elucidation.

\subsection{Limitations of the study}

Data was only collected from three conveniently selected universities out of the 35 universities. The sample did not reflect proportional representation of the entire study population as students from the professional or the sciences, postgraduate school and long distance students were not included in the sample. This may limit the generalization of these results.

\section{Conclusion}

This study provides some preliminary and concerning data on the psychosocial and psychopathological state of university students in Uganda. Students exposed to psychosocial problems also indicated a psychopathological state of depression and anxiety.

\subsection{Implications of the study}

This study found that $37 \%$ of the studied university students had significant psychosocial problems leading to the development of psychopathology (depression, anxiety) in $34.8 \%$ of the students. This suggests a need for effective mental health screening and provision of mental health services at universities. Psychosocial problems and psychopathology are mental health issues present at university campuses in Uganda. Therefore university administration has to intervene in the present mental health situation on university campuses by setting up policy measures that can collaboratively identify acceptable treatment pathways to address vulnerable students

Assessment of student psychosocial problems should be a routine service for student medical checkups. The USEPP is one such instrument and not to wait for full blown psychopathological state before intervention. Students and faculty should be helped in acquiring and improving knowledge about the student mental health issues as a crucial factor in the development of mental health promotion programs in order to meet their needs and to help them cope with various psychosocial problems. Better understanding and care of university students' mental health can be helpful in social integration, academic and career choice and prevention of future mental health problems. Mental health awareness among faculty should be integrated in staff development courses in order to equip them with skills to effect informed referrals of vulnerable students to professional mental health personnel. Further research is needed to examine the prevalence and correlates of psychosocial problems among the Uganda university students to further help guidance counsellors elucidate on the ways to reduce/prevent students' psychosocial problems.

\section{References:}

Ahmad, A., Khalique, N., Khan, Z., \& Amir, A. (2007). Prevalence of psychosocial problems among school going male adolescents. Indian Journal of Community Medicine, 32, 219-221. 
Psychosocial problems and development of psychopathology among Ugandan university students http://dx.doi.org/10.4103/0970-0218.36836

American College Health Association (ACHA) (2006). American College Health Association National College Health Assessment Spring 2006 Reference Group data report (abridged). Journal of America College Health, 55(4), 195-206.

Betancourt, T. S., Speelman, L., Onyango, G., \& Bolton, P. (2009). Psychosocial problems of war-affected youth in Northern Uganda: A qualitative study. Transcult Psychiatry, 46(2), 238-256. http://dx.doi.org/10.1177/1363461509105815

Blanco, C., Okuda, M., Wright, C., Hasin, D. S., Grant, B. F., Liu, S., \& Olfson, M. (2008). Mental health of college students and their non-college-attending peers: Results from the national epidemiologic study on alcohol and related conditions. Archives of General Psychiatry, 65, 1429-1437.

http://dx.doi.org/10.1001/archpsyc.65.12.1429

Blignault, I., Bunde-Birouste, A., Ritchie, J., Silove, D., \& Zwi, B. A. (2009). Community perceptions of mental health needs: A qualitative study in the Solomon Islands. Retrieved December 13, 2012, from http://www.ijmhs.com/content/pdf/1752-4458-3-6.pdf

Bodas, J. (2003). The moderating role of anxiety in predicting academic achievement in children. Unpublished Masteral thesis, Faculty of Virginia Polytechnic Institute, Virginia State University, U.S.A.

Brackney, B. E., \& Karabenick, S. A. (1995). Psychopathology and academic performance: The role of motivation and learning strategies. Journal of Counselling Psychology, 42(4), 456-465. http://dx.doi.org/10.1037/0022-0167.42.4.456

Buckley, J. A. (2009). Implementing evidence-based interventions in elementary schools for students with and at risk for severe behavior disorders. Journal of Emotional and Behavioral Disorders, 17(4), 195-196. http://dx.doi.org/10.1177/1063426609345866

Cornah, D. (2006). The impact of spirituality upon mental health: A review of the literature. Retrieved February 8,2012 , from http://socialwelfare.bl.uk/subject-areas/services-client-groups/adults-mental-health/mentalhealthfoundat ion/1526282006_impact_spirituality.pdf

Dusselier, L., Dunn, B., Wang, Y., Shelley, M. C., \& Whalen, D. F. (2005). Personal, health, academic, and environmental predictors of stress for residence hall students. Journal of American College Health, 54, 15-24. http://dx.doi.org/10.3200/JACH.54.1.15-24

Eisenberg, D., Gollust, S. E., Golberstein, E., \& Hefner, J. L. (2007). Prevalence and correlates of depression, anxiety, and suicidality among university students. American Journal of Orthopsychiatry, 77(4), 534-542. http://dx.doi.org/10.1037/0002-9432.77.4.534

Ellison, K. W. (2004). Stress and the police officer ( $2^{\text {nd }}$ ed.). Springfield, IL: Charles C. Thomas Publishers.

Engel, L. G. (1977). The need for a new medical model: A challenge for biomedicine. Science, New Series, 196(4286), 129-136.

Gallanger, R. P. (2005). National survey of counselling center directors. Alexandria, VA: International Association of Counselling Services, Inc.

Gallagher, R. P. (2006). National Survey of Counseling Center Directors. Alexandria, VA: International Association of Counseling Services Inc.

Gallagher, R. P., Zhang, B., \& Taylor, R. (2004). National survey of counseling center directors (Monograph Series No. 8N). Alexandria, VA: International Association of Counseling Services, Inc.

Harper, R., \& Peterson, M. (2005). Mental health issues and college students. NACADA Clearinghouse of Academic Advising Resources. Retrieved January 10, 2011, from http://www.nacada.ksu.edu/clearinghouse/advisingissues/mental-health.htm

Hasin, D. S., Stinson, F. S, Ogburn, E., \& Grant, B. F. (2007). Prevalence, correlates, disability, and comorbidity of DSM-IV alcohol abuse and dependence in the United States-results from the National Epidemiologic Survey on Alcohol and Related Conditions. Archives of General Psychiatry, 64, 830-842. http://dx.doi.org/10.1001/archpsyc.64.7.830

Holmes, A., Silvestri, R., \& Kostakos, M. (2011). The impact of mental health problems in the community college student population. Toronto: Higher Education Quality Council of Ontario. 
Nsereko, N. D., Musisi, S., Nakigudde, J., \& Ssekiwu, D.

Hunt, J., \& Eisenberg, D. (2010). Mental health problems and help-seeking behavior among college students. Journal of Adolescent Health, 46, 3-10. http://dx.doi.org/10.1016/j.jadohealth.2009.08.008

Kadison, R., \& DiGeronimo, T. F. (2004). College of the overwhelmed: The campus mental health crisis and what to do about it. San Francisco: Jossey-Bass.

Kendall, P. C., \& Dobson, K. S. (1993). On the nature of cognition and its role in psychopathology, (pp. 3-17) In K. S. Dobson \& P. C. Kendall (Eds.) Psychopathology and Cognition. San Diego, CA: Academic Press.

Kneser, G. (2004, April). College students leading hyper-enriched lives. St. Olaf E-newsletter. Retrieved March 20, 2011, from http://www.stolaf.edu/president/enewsletter/0404.html\#2

Kettmann, J. J. D., Schoen, E. G., Moel, J. E., Cochran, S. V., Greenberg, S. T., \& Corkery, J. M. (2007). Increasing severity of psychopathology at counseling centers: A new look. Professional Psychology: Research and Practice, 38(5), 523-529. http://dx.doi.org/10.1037/0735-7028.38.5.523

Kisch, J., Leino, E. V., \& Silverman, M. M. (2000). Aspects of suicidal behavior, depression, and treatment in college students: Results from the spring, national college health assessment survey. Suicide Life Threatening Behaviour, 35, 3-13. http://dx.doi.org/10.1521/suli.35.1.3.59263

Kitzrow, M. A. (2003). The mental health needs of today's college students: Challenges and recommendations. Retrieved June 20, 2012, from http://depts.washington.edu/apac/roundtable/1-23-07_mental_health_needs.pdf

Laelia, G., Apicella, L., Brakarsh, J., Dube, L., Jemison, K., Kluckow, M., Smith, T., \& Snider, L. (2006). Orphans and vulnerable youth in Bulawayo, Zimbabwe: An exploratory study of psychosocial well-being and psychosocial support. Retrieved June 18, 2012, from http://www.popcouncil.org/pdfs/horizons/zimorphans.pdf

Loeber, R., \& Farrington, D. P. (1998). Never too early, never too late: Risk factors and successful interventions for serious and violent juvenile offenders. Studies on Crime and Crime Prevention, 7, 7-30.

Lucas, C. J. (1976). Aspects of student health psychological problems of students. British Medical Journal, 2 , 1431-1433. http://dx.doi.org/10.1136/bmj.2.6049.1431

Md Yasin, A. S., \& Dzulkifli, M. A. (2009). Differences in psychological problems between low and high achieving students. The Journal of Behavioral Science, 4(1), 49-58.

Mikolajczyk, R. T., Brzoska, P., Maier, C., Ottova, V., Meier, S., Dudziak, U., Ilieva, S., \& El Ansari, W. (2008). Factors associated with self-rated health status in university students: A cross-sectional study in three European countries. Public Health, 8, 215-225.

Miller, J. L., Schmidt, L. A., \& Vaillancourt, T. (2008). Shyness, sociability, and eating problems in a nonclinical sample of female undergraduates. Eating Behaviour, 9, 352-359. http://dx.doi.org/10.1016/j.eatbeh.2008.01.001

Mowbray, C. T., \& Holter, M. C. (2002). Mental health and mental illness: Out of the closet? Social Science Review, 76(1), 135-179.

Nsereko, N., Musisi, S., \& Holtzman, S. (in press). Evaluation of psychosocial problems among African university students in Uganda: Development and validation of a screening instrument.

Offord, D. R., \& Bennett, K. J. (1994). Conduct disorder: Long-term outcomes and intervention effectiveness. Journal of American Academy of Child and Adolescent Psychiatry, 33(8), 1060-1078. http://dx.doi.org/10.1097/00004583-199410000-00001

Omokhodion, F., \& Gureje, O. (2003). Psychosocial problems of clinical students in the University of Ibadan. African Journal of Medicine and Medical Sciences, 32(1), 55-68.

Ontari, H., \& Angolla, J. E. (2008). Occupational stress in organizations and its effects on organizational performance. Journal of Management. Research, 8(3), 123-135.

Ovuga, E., Boardman, J., \& Wasserman, D. (2006). Undergraduate student mental health at Makerere University, Uganda. World Psychiatry, 5(1), 51-52.

Pickard, J. G., \& Tang, F. Y. (2009). Older adults seeking mental health counseling in a NORC. Research on Aging, 31(6), 638-660. http://dx.doi.org/10.1177/0164027509343539

Pledge, D., Lapan, R., Heppner, P., \& Roehlke, H. (1998). Stability and severity of presenting problems at a university counselling center: A 6-year analysis. Professional Psychology Research and Practice, 24(4), 
Psychosocial problems and development of psychopathology among Ugandan university students

386-389. http://dx.doi.org/10.1037/0735-7028.29.4.386

Reijneveld, S. A., Vogels, A. G. C., Brugman, E., Van Ede, J., Verhulst, F. C., \& Verloove-Vanhorick, S. P. (2003). Early detection of psychosocial problems in adolescent. How useful is the Dutch short indicative questionnaire (KIVPA)? European Journal of Public Health, 13, 152-159.

http://dx.doi.org/10.1093/eurpub/13.2.152

Renu, S., \& Manju, D. (2013). Spiritually and mental health among normal and chronic disease group. International Journal of Research Studies in Psychology, 2(1), 59-68.

Robins, L. N., \& Price, R. K. (1991). Adult disorders predicted by childhood conduct problems: Results from the NIMH Epidemiologic Catchment Area project. Psychiatry, 54, 116-132.

Salzer, M. S. (2012). A comparative study of campus experiences of college students with mental illnesses versus a general college sample. Journal of American College Health, 60(1), 1-7. http://dx.doi.org/10.1080/07448481.2011.552537

Sherina, M. S., Med, M., Rampal, L., \& Kaneson, N. (2004). Psychological stress among undergraduate medical students. Medical Journal of Malaysia, 59(2), 207-211.

Silverman, M. M., Meyer, P. M., Sloane, F., Raffel, M., \& Pratt, D. M. (1997). The big ten student suicide study: A 10-year study of suicides on Midwestern university campuses. Suicide Life Threatening Behaviour, $27,285-303$.

Smart, D., Vassallo, S., Sanson, A., \& Dussuyer, I. (2004). Patterns of antisocial behaviour from early to late adolescence. Trends \& issues in crime and criminal justice. Australian Institute of Criminology, 209, $1-6$.

Stallman, H. M. (2008). Prevalence of psychological distress in university students: Implications for service delivery. Australian Family Physician, 3(8), 673-677.

Stepakoff, S. (1998). Effects of sexual victimization on suicidal ideation and behavior in U.S. college women. Suicide Life Threatening Behaviour, 28, 107-126.

Stone, G. L., \& Archer, J. Jr. (1990). College and university counselling centers in the 1990's: Challenges and limits. The Counselling Psychologist, 18, 539-618. http://dx.doi.org/10.1177/0011000090184001

Storrie, K., Ahern, K., \& Tuckett, A. (2010). A systematic review: Students with mental health problems--a growing problem. International Journal of Nursing Practice, 16(1), 1-6. http://dx.doi.org/10.1111/j.1440-172X.2009.01813.x

Svanum, S., \& Zody, Z. (2001). Psychopathology and college grades. Journal of Counselling Psychology, 48, 72-76. http://dx.doi.org/10.1037/0022-0167.48.1.72

Tosevski, D. L., Milovancevic, M. P., \& Gajic, S. D. (2010). Personality and psychopathology of university students. Current Opinion in Psychiatry, 23, 48-52. http://dx.doi.org/10.1097/YCO.0b013e328333d625

Uganda National Council for Science and Technology (UNCST) (2011). Science, technology and innovation in Uganda: Status report, 2009/2010. Retrieved December 21, 2012, from http://www.uncst.go.ug/dmdocuments/2010-2011\%20STI\%20Report.pdf

Van Niekerk, L., Viljoen, A. J., Rischbleter, P., \& Scribante, L. (2008). Subjective experience of depressed mood among medical students at the University of Pretoria. South African Journal of Psychology, 14(1), 27-31.

Waddell, C., Lipman, E., \& Offord, D. R. (1999). Conduct disorder: Practice parameters for assessment, treatment and prevention. Canadian Journal of Psychiatry, 44, 35S-42S.

Weitzman, E. R. (2004). Poor mental health, depression, and associations with alcohol consumption, harm, and abuse in a national sample of young adults in college. Journal of Nervous Mental Disorders, 192, 269-277. http://dx.doi.org/10.1097/01.nmd.0000120885.17362.94

Williams, K. L., \& Galliher, R. V. (2006). Predicting depression and self-esteem from social connectedness, support, and competence. Journal of Social and Clinical Psychology, 25, 855-874.

http://dx.doi.org/10.1521/jscp.2006.25.8.855 
Appendix A

\section{SOCIAL DEMOGRAPHIC INFORMATION}

Please answer as required by circling / filling in the gaps where appropriate.

1. Gender: (a) Male (b) Female

2. Age: $\leq 24, \quad 25-29, \quad 30-34, \quad 35-39, \geq 40$

3. Religious affiliation: (a) Moslem (b) Church of UG (c) Catholic (d) Born Again (e) Other (specify)

4. Nationality: (a) Ugandan (b) Other (specify)

5. Marital Status: (a) Single (b) Married (c) other(specify)

6. University Residence Location: (a) On-campus residence (b) Off-campus hostel (c) Other (specify)

7. Program of Study: (a) Day (b) Weekend (c) Evening

8. Years in University: (a) $1^{\text {st }}$-year (b) $2^{\text {nd }}$ year (c) $3^{\text {rd }}$ year (d) $4^{\text {th }}$ year (e) 5 th year

9. Course of study:

10. Living with parents (a) yes (b) No

11. Education Sponsorship: (a) Parents (b) Relative (c) Government (d) Other (specify)

12. Is the income level of your parents able to support you at university? (a)Yes (b) Yes but with difficulty (c)Not able 
Appendix B

UNIVERSITY STUDENTS EVALUATION OF PSYCHOSOCIAL PROBLEMS (USEPP)

You are asked to go through the issues/concerns listed below. Indicate your level of agreement with those that are current concerns for you by circling the number on your right from the following options: Not at all $=0$; Somewhat Agree $=1 ;$ Agree $=2 ;$ Strongly Agree $=3$

Circle one response for each item and do not leave any blank

\begin{tabular}{|c|c|c|c|c|}
\hline Issues/concerns experienced and are current concerns for me & & & & \\
\hline Feeling stressed, being in low mood & $\mathbf{0}$ & 1 & 2 & 3 \\
\hline Unpredictable/Insecure tuition fees status & $\mathbf{0}$ & 1 & 2 & 3 \\
\hline I am involved in behaviours I should be ashamed of if they became public & $\mathbf{0}$ & 1 & 2 & 3 \\
\hline I am not able to concentrate on my studies as I would have liked & $\mathbf{0}$ & 1 & 2 & 3 \\
\hline Experiences of irrational fears/phobia & $\mathbf{0}$ & 1 & 2 & 3 \\
\hline For this number just shade all the boxes & $\mathbf{0}$ & 1 & 2 & 3 \\
\hline Often lacking welfare/pocket money for personal use & $\mathbf{0}$ & 1 & 2 & 3 \\
\hline Involved in one way or the other in academic mal practice & $\mathbf{0}$ & 1 & 2 & 3 \\
\hline Low academic grades & $\mathbf{0}$ & 1 & 2 & 3 \\
\hline Sometimes experiencing wishes of being dead & $\mathbf{0}$ & 1 & 2 & 3 \\
\hline Adjustment problems in my new environment i.e hostel, campus life & $\mathbf{0}$ & 1 & 2 & 3 \\
\hline I take sexual advantage of others & $\mathbf{0}$ & 1 & 2 & 3 \\
\hline Inadequate study skills to meet university academic demands & $\mathbf{0}$ & 1 & 2 & 3 \\
\hline I have problems of concentrating in life generally & $\mathbf{0}$ & 1 & 2 & 3 \\
\hline For this number just shade all the boxes & $\mathbf{0}$ & 1 & 2 & 3 \\
\hline My family is experiencing problems to which I am of great concern & $\mathbf{0}$ & 1 & 2 & 3 \\
\hline Gambling/betting for financial gain & $\mathbf{0}$ & 1 & 2 & 3 \\
\hline I sometimes find it difficult to sleep or I sleep too much & $\mathbf{0}$ & 1 & 2 & 3 \\
\hline Uncontrolled drinking of alcohol & $\mathbf{0}$ & 1 & 2 & 3 \\
\hline
\end{tabular}




\section{Appendix C}

\section{HOPKINS SYMPTOMS CHECKLIST (HSCL-10)}

You are asked to respond to the following items according to your experience during the previous week by indicating the answer you think most applies to you: write only the number in the corresponding box. $1=$ Not At All; 2= Somehow Agree; 3= Agree; 4= Extremely Agree

During the last week you were,

a. Suddenly scared for no reason

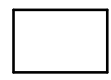

b. Feeling fearful

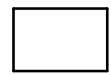

c. Feeling dizziness, or weakness

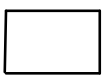

d. Feeling tense

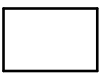

e. Blaming yourself for things

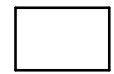

f. Difficulty in falling asleep or staying asleep

g. Feeling depressed/down

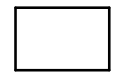

h Feeling of worthlessness

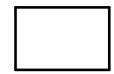

i. Feeling everything is an effort

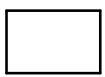

j. Feeling hopeless about future 